\title{
Paulo Freire e o consenso progressivo na gestão da educação municipal em São Paulo. A cunha e o formão
}

\author{
Paulo Freire and the progressive consensus in the management of municipal \\ education in São Paulo. The wedge and chisel
}

Paulo Freire y el consenso progresista en la gestión de la educación municipal en São Paulo. La cuña y el cincel

\author{
CELIA BENEDICTO GIGLIO \\ https://orcid.org/0000-0002-6627-5459 \\ Universidade Federal de São Paulo \\ Escola de Filosofia, Letras e Ciências Humanas \\ Departamento de Educação \\ São Paulo, SP, Brasil \\ MARCOS MENDONCCA \\ https://orcid.org/0000-0002-7839-6952 \\ Universidade de São Paulo \\ Faculdade de Educação \\ Departamento de Educação \\ São Paulo, SP, Brasil
}

\begin{abstract}
Resumo: $\mathrm{O}$ artigo parte da experiência de gestão dos autores, da pesquisa documental e bibliográfica, com o objetivo de relatar o percurso de implementação da política municipal de educação desenvolvida na região do Núcleo de Ação Educativa - NAE-10 (São Miguel Paulista - São Paulo) na gestão Paulo Freire. Analisa as estruturas de gestão desenvolvidas para fazer dialogar: o local e o central; pontua práticas de construção do consenso progressivo nesses níveis de governo e desafios correspondentes. Apresenta um balanço provisório das lutas e das apropriações desse legado à população e à educação na região.
\end{abstract}

Palavras-chave: Paulo Freire, gestão de sistemas de ensino, gestão democrática, consenso progressivo, educação escolar.

\begin{abstract}
The article starts from the authors' management experience and from documentary and bibliographic research aiming at reporting the municipal education policy implementation in the region of Educational Action Center - NAE-10 (São Miguel Paulista - São Paulo) during the administration of Paulo Freire. It analyzes the management structures developed to stimulate the dialogue between the local and the central; points out the building practices of progressive consensus at these government levels and the corresponding challenges. It presents a provisional assessment of the struggles and appropriations of this legacy for the population and education in the region.
\end{abstract}

Keywords: Paulo Freire, educational systems management, democratic management, progressive consensus, school education 
Resumen: El artículo parte de la experiencia de gestión de los autores, a partir de la investigación documental y bibliográfica, con el objetivo de reportar la trayectoria de implementación de la política educativa municipal desarrollada en la región de Centro de Acción Educativa - NAE-10 (São Miguel Paulista - São Paulo) bajo la dirección de Paulo Freire. Analiza las estructuras de gestión desarrolladas para hacer el diálogo entre lo local y lo central, señala las prácticas de construcción de consensos progresivos en esos niveles de gobierno y los desafíos correspondientes. Presenta un balance provisional de las luchas y apropiaciones de ese legado para la población y para la educación en la región.

Palabras clave: Paulo Freire, gestión de sistemas de enseñanza, gestión democrática, consenso progresista, educación escolar.

\section{INTRODUÇÃO}

O ano de 2021, centenário de nascimento de Paulo Freire, oferecenos oportunidade singular para refletir a gestão Paulo Freire à frente da Secretaria Municipal de Educação (SME) de São Paulo entre 1989-1991, com foco na dimensão da gestão da educação municipal na cidade, que implicou na organização de equipes de trabalho e estruturas que permitissem povoar todas as instâncias da secretaria de educação do sonho possível de transformar a cultura da administração pública na cidade, e fundar uma nova qualidade na relação entre governo e população. Essa nova qualidade estava no diálogo permanente e no aprendizado da participação; o desafio foi enfrentado e contou, na SME, com o primado do consenso progressivo, guiado pelo mestre do diálogo, Professor Paulo Freire. ${ }^{1}$

Democratizar a gestão da escola era também democratizar a gestão da própria SME, fundando novas relações entre as instâncias centrais e locais, criando estruturas intermediárias em cada região da cidade - os Núcleos de Ação Educativa (NAE) - e uma aproximação orgânica com as escolas, seus profissionais e comunidades. A reorganização da SME, em 1989, criou novos dispositivos de gestão para um exercício amplo de interações dialógicas e participação - a gestão democrática - em todos os níveis a partir da colegialidade.

1 A premissa epistemológica do diálogo tem centralidade no pensamento e em obras de Paulo Freire, desde aquelas abordaram as experiências de educação e cultura popular no Recife/PE e Angicos-RN, nos anos 1950 e 1960, nas iniciativas de alfabetização de jovens e adultos em países que passaram por processos de independência política em África, ao final dos anos 1970, e no contexto da SME/SP em 1989-1991. 
Os três colegiados de caráter deliberativo - central, intermediário e local correspondiam aos níveis de decisão existentes na estrutura da Secretaria. O colegiado central reunia os representantes do gabinete e os representantes do colegiado intermediário composto do representante da Coordenadoria dos Núcleos de Ação Educativa - CONAE e dos representantes dos Núcleos de Ação Educativa - NAE, além de um membro da Assessoria Técnica de Planejamento - ATP. (GADOTTI, JACOBI p. 65)

A democratização do acesso, para além da necessária expansão da rede física de escolas, exigiu recuperar as escolas existentes nos aspectos das condições materiais e pedagógicas; conhecer as escolas e suas lógicas de funcionamento, o uso dos espaços e tempos - recursos essenciais à ampliação do atendimento, e o estabelecimento do diálogo e cooperação com a rede estadual de ensino no território para alcançar o máximo atendimento a crianças, adolescentes, jovens e adultos.

A nova qualidade de ensino estava articulada às diretrizes anteriores, ancorava-se na visão de que todas as crianças, jovens e adultos têm direito à educação significativa, inclusiva e multicultural; desse modo, os educadores foram chamados a tomar parte do processo da renovação curricular e metodológica, partindo do que já havia sido produzido entre 1983 e 1985. A Rede foi desafiada a criar coletivamente um sentido novo ao aprendizado escolar e a experimentar nova ordenação do conhecimento, concebido em ciclos de aprendizagem.

Tendo a Constituição Federal de 1988 (CF/88) estabelecido a obrigatoriedade e gratuidade do ensino fundamental, inclusive para os que a ele não tiveram acesso na idade própria (BRASIL, 1988), ${ }^{2}$ uma política de educação de jovens e adultos foi construída a partir do complexo diálogo entre os Movimentos Populares de Alfabetização (MOVA), o Programa de Educação de Adultos (EDA) a cargo da Secretaria do Bem Estar Social até julho de 1989, além da Suplência I e II presente nas escolas municipais no turno noturno, estabelecendo parcerias entre movimentos populares e poder público. ${ }^{3}$

Quatro diretrizes, quatro grandes desafios que só puderam ser assumidos pela ousadia de Paulo Freire e sua equipe em implantar práticas participativas em todas as instâncias, materializando as bases para uma comunicação dialógica como práxis em sua gestão.

$2 \quad$ Inciso I do Art. 208; essa obrigatoriedade foi alterada pela Emenda Constitucional no 59 de 2009 tornando a educação básica obrigatória e gratuita dos 4 aos 17 anos de idade (BRASIL, 2009).

3 O Programa EDA teve origem no MOBRAL/Fundação Educar após sua extinção em 1990; correspondia ao primeiro segmento do ensino fundamental e era ofertado por entidades conveniadas. Foi transferido para a SME pelo decreto $\mathrm{n}^{\circ} 27.911$ de 27/07/1989 e conviveu com a Suplência I e II, de oferta direta da SME nas escolas municipais (HADDAD; DI PIERRO, 2000; FARIA, 2014). 
Nosso papel não é falar ao povo sobre a nossa visão do mundo, ou tentar impôla a ele, mas dialogar com ele sobre a sua e a nossa. Temos de estar convencidos de que a sua visão do mundo, que se manifesta nas várias formas de sua ação, reflete a sua situação no mundo, em que se constitui. A ação educativa e política não pode prescindir do conhecimento crítico dessa situação, sob pena de se fazer "bancária" ou de pregar no deserto. (FREIRE, 1987, p. 87).

Arelaro (2019, p. 307, grifos da autora) sintetiza o sentido político da gestão democrática e participativa como prioridade da administração da Prefeita Luiza Erundina e da SME com Paulo Freire Secretário Municipal de Educação: "Não se pretendia, de forma nenhuma, 'gerir o capitalismo', mas enfrentá-lo, procurando reduzir seus efeitos perversos por meio de ações e projetos que oferecessem melhores condições de vida à maioria (pobre) da e junto com a população".

No século XXI, parece já uma banalidade falar em gestão democrática, e talvez seja esse o principal motivo para relembrar momentos em que essas duas palavras invadiram o espaço da administração municipal de São Paulo e ganharam corpo na SME entre 1989 e 1992, diretamente relacionadas ao que Paulo Freire defendeu em seus escritos: a ação direta produzida por meio do diálogo, corporificada em uma prática de respeito à capacidade de todos tomarem parte das decisões que interferem na vida e na conquista do direito pleno à cidadania.

Nosso objetivo é relatar o processo de gestão da educação municipal a partir do Núcleo de Ação Educativa 10 (NAE-10), na região de São Miguel Paulista, entre 1989 e 1992, em especial o âmbito da participação na busca do aprendizado da gestão democrática, seus desafios e legado. O artigo apresenta antecedentes históricos e o contexto da região do NAE-10 a partir dos movimentos populares, retoma a arquitetura da SME após sua reestruturação para a construção do diálogo em rede e suas estruturas decisórias. A partir da metáfora da cunha e do formãa $0^{4}$, narra as tensões ocorridas no percurso dessa construção, demonstrando que as forças presentes - por vezes contraditórias - reavivaram novas e velhas fórmulas de enfrentamento às resistências diante de um novo cenário de direitos inscritos na $\mathrm{CF} / 88$. Com centralidade nas práticas de planejamento para atender a demanda regional por vagas no NAE-10, aborda a rede de ações implicadas na busca de materializar a Gestão Democrática da escola e a Democratização do acesso à escolarização. Finaliza apontando o legado da gestão de Paulo Freire na

4 A metáfora referida às ferramentas nomeadas cunha e formão (artefatos da cultura, desde a artesania) é utilizada aqui tal como a sabedoria popular o faz: aplicando a função das ferramentas de trabalho e sua manipulação, em sentido figurado, às relações sociais desenvolvidas entre os humanos em sociedade, espécie de artesania social, processo de produção de relações que cria a necessidade de forjar maneiras adequadas à superação ou solução de problemas. 
região, com destaque ao fortalecimento e ampliação do Movimento de Educação da Zona Leste (MEZL) e ao importante aprendizado da participação nas escolas, entre educadores e educandos, na luta permanente por mais cidadania.

\section{LUTAS POR EDUCAÇÃO NA ZONA LESTE E O TEMPO DE ESPERANÇAR}

A região administrativa e geográfica, que correspondeu ao NAE- 10, situado num dos extremos leste de São Paulo, abarcava à época os bairros de Itaim Paulista, São Miguel Paulista e Ermelino Matarazzo; a área geográfica abrangida correspondia àquela de responsabilidade da Administração Regional de São Miguel Paulista.

Os desafios regionais espelhavam um território com população extremamente adensada que convivia com inúmeros problemas urbanos, principalmente carência de equipamentos públicos capazes de estender direitos sociais à população. No âmbito educacional, faltavam escolas públicas que atendessem o ensino básico e os elevados índices de analfabetismo entre jovens e adultos.

Contrastando com esse cenário, a população exigia melhores condições de subsistência; os anos 1980 alavancaram a organização de movimentos populares reivindicatórios na região, voltados à conquista da cidadania plena. A crise urbana fez surgir novas modalidades de ações coletivas, movimentos populares e Movimentos Sociais Urbanos de base local. Castells (1980) tratou dos movimentos urbanos valorizando seu potencial político nos processos de transformação social; sua análise acerca da potência política do movimento citadino descreve em certa medida o que ocorria na região. Vários movimentos emergiram ao mesmo tempo: o movimento de saúde, organizado por profissionais da saúde e populares, reivindicava atendimento à saúde próximo às suas comunidades; o movimento de educação, liderado por mulheres que, além de lutar por vagas nas escolas públicas, denunciaram a cobrança de taxas às Associações de Pais e Mestres de escolas que muitas vezes vinculavam a matrícula à abusiva obrigatoriedade de contribuição. (RIBEIRO, 1986).

A ampliação das oportunidades educacionais, a recuperação e manutenção das escolas públicas, além das condições de permanência de todos nas escolas tornaram-se as pautas principais do MEZL; a participação nas unidades educacionais e nas decisões do espaço governamental da rede pública na região também estiveram presentes. 
A pauta do movimento de educação era decidida com participação da população, discutiam-se estratégias de atuação junto às autoridades regionais ou centrais, para apresentação das demandas. A mecânica de operação estabelecia a conquista de garantia de recursos como meta. Ao lutar por escola e educação, o povo buscava melhor qualificação, acesso a melhores e maiores oportunidades de inserção no mundo do trabalho formal.

O MEZL mantinha reuniões em salões comunitários, principalmente na Paroquia São Francisco de Assis, onde o padre Antonio Luís Marchione conhecido como Padre Ticão ${ }^{5}$-, apoiava e organizava grupos que se reuniam por áreas de reivindicação. Outros organizadores atuavam junto aos agentes ligados à igreja católica à época sob orientações da Teologia da Libertação, além de partidos de esquerda, cujos militantes tomavam parte das lutas sociais de movimentos populares e dos emergentes movimentos sociais no período. A eleição da Prefeita Erundina contou com participação direta dos movimentos na região, vislumbrando atendimento de suas reinvindicações; uma mulher no poder ${ }^{6}$ conferiu significado especial ao movimento: a possibilidade concreta de o povo popular participar das decisões sobre políticas públicas no governo municipal. No campo da Educação vislumbrou-se a criação de espaços de participação social nas escolas, no movimento sindical do magistério municipal e no movimento de educação. Paulo Freire, a frente da SME de São Paulo, dava concretude ao verbo esperançar e consolidava essas expectativas.

\section{A POLÍTICA EDUCACIONAL PROPOSTA E ALGUNS DESAFIOS PARA A SUA CONCRETIZAÇÃO NA CIDADE}

Com o objetivo de analisar a gestão da política educacional em São Paulo durante a gestão de Paulo Freire, a partir do NAE-10, retomamos as estruturas que organizavam a atuação dos agentes centrais e locais para realizar tal política na dimensão teórico-prática, que envolve a concepção e reinvenção de tempos e espaços de poder e gestão, contextualizando a cultura política na qual a administração da educação na cidade foi marcada e o choque de culturas administrativas e de gestão de políticas que foram vivenciadas naquele momento. Relações burocratizadas e a tradição verticalizada da gestão municipal instituíram relações de submissão entre os níveis central e local, entre aqueles que podem pensar e os que devem executar e sofrer os efeitos das políticas. Esse modelo,

5 Antonio Luiz Marchione - Padre Ticão (1955 - 2021) - chegou à Paroquia São Francisco de Assis em Ermelino Matarazzo em 1980, atuou fortemente na organização de movimentos populares que transformaram a região em muitas áreas sociais. 
na dimensão local da rede de ensino, reproduziu uma visão naturalizada das relações de poder em que as funções dos organismos intermediários de gestão as Delegacias Regionais de Ensino Municipal (DREM) - eram de replicação das normas e fiscalização da execução; sob a austeridade da autoridade constituída, também acolhiam o patrimonialismo como parte da cultura que ainda se fazia fortemente presente nas relações em 1989.

Em resposta a esse modelo, a criação dos NAE teve como objetivo reinventar as instâncias intermediárias de gestão entre a SME, seus diversos órgãos centrais e as escolas municipais, criando as condições para o estabelecimento do diálogo necessário à democratização da gestão e à descentralização. Os NAE também tiveram o importante papel de participar do planejamento regional conjunto e atuar de modo articulado aos demais serviços públicos de responsabilidade municipal. Essa experiência se deu pela criação dos Núcleos Regionais de Planejamento - NRP, criados em março de 1989.

A gestão da educação na cidade sob a liderança de Paulo Freire estabeleceu não apenas uma dinâmica sociopolítica e educativa e uma agenda de aproximação com as escolas, os profissionais, estudantes e comunidades; estabeleceu o desafio de tomar parte na proposta de inversão de prioridades em favor do setor popular na gestão da cidade, na medida em que essa foi a meta do governo: "instaurar uma prática de gestão municipal que dialogasse com as demandas dos cidadãos e democratizasse o processo de tomada de decisões, superando o clientelismo e o autoritarismo". (MARTINS, 1997, p.5)

No período, a gestão do sistema municipal de ensino catalisava as condições de inversão de prioridades na cidade, visto que a capilaridade de suas ações envolvia tanto agentes públicos, como usuários das escolas em práticas participativas, alterando padrões de comportamento vinculados à participação. Foram recriadas estruturas e estabelecidas formas de gestão participativas que colocavam em diálogo órgãos centrais e intermediários: Gabinete, CONAE, NAE, Conselho de Representantes de Conselhos de Escola (CRECE), Conselho de Escola (CE). Localmente os NAE estabeleceram mecanismos de participação ativa das escolas por suas representações; nas escolas da rede podemos citar processos amplos de discussão e elaboração de um novo Regimento, de um Estatuto do Magistério Público Municipal e na elaboração do Orçamento da SME.

Arelaro (2019, p. 309) relata que, no primeiro dia do governo na gestão Erundina/ Freire, 1\% 01/1989, publicou-se em ato, em Diário Oficial da cidade, a recuperação e devolução às escolas das Propostas curriculares' e do decreto que estabelecia o 'Regimento das Escolas Municipais' que haviam sido escritos com a participação de muitos professores da Rede e discutidos com o conjunto dos profissionais da educação no governo 
Covas (1983/85) ; descreve ainda o cenário de horror praticado pela gestão Jânio Quadros que mandou recolher e queimar, ou vender a "preço de paina" as publicações das Propostas Curriculares. Muitos outros desafios de gestão, inclusive aqueles decorrentes de demandas impostas pela nova $\mathrm{CF} / 88$, impuseram demandas políticas e técnicas gigantescas para a administração e para a SME na implementação das diretrizes da Educação no Município.

A partir da CF/88 tornou-se obrigatório realizar concursos públicos para admissão de servidores; tal norma afetou imediatamente toda a gestão pública no sentido de dar providências aos ajustes necessários. A administração municipal possuía importante quantidade de servidores sem estabilidade. Situação que a gestão Freire enfrentou de início, mas com duplo problema: o primeiro foi a grande quantidade de servidores com baixa escolaridade que ingressaram sem concurso e que não se enquadravam nas condições de estabilidade; o segundo foi a peculiaridade na contratação temporária de professores para a educação infantil e o ensino fundamental, que eram contratados em "cargos em comissão" (ARELARO, 2019, p. 316), o que os excluía da estabilidade mesmo com cinco anos ou mais de atividade na SME, em razão do tipo de contratação praticada que, juridicamente, não os caracterizava como servidores públicos, mas como de "confiança da administração" - ainda que as contratações tenham obedecido critérios objetivos de classificação e nomeação, (Ibid, p. 317). O Secretário e educador Paulo Freire, segundo Arelaro, enfrentou essa injustiça demandando correção da flagrante distorção de contrato; a justeza e legalidade dessa correção deu-se em 1992, último ano do governo, reconhecendo cerca de mil professores como "estáveis" no serviço municipal. (Ibid, p. 318).

Ao lado de questões da dimensão narrada acima, no plano local, destacamos os desafios para o planejamento ao atendimento à demanda do território, com participação direta e articulada dos diretores municipais e estaduais para concretizar os princípios da gestão Freire na SME:

Três princípios básicos norteiam a política desta administração: participação, descentralização e autonomia. $\mathrm{Na}$ tradição política brasileira, participação tem significado apenas a discussão de problemas, sem acesso a decisões e, por descentralização, entende-se a execução de tarefas já decididas. A atual administração acredita que participação e descentralização implicam autonomia para que as escolas tomem decisões em conjunto com os órgãos centrais da Secretaria da Educação. (SÃO PAULO. SME, 1990, p. 4).

As vivências nessa gestão constituíram-se uma escola para todos, foram sucessivos exercícios de aproximação e construção de experiências dialógicas, de vivência de relações democráticas. Destaca-se o consenso progressivo como 
a maior aprendizagem democrática construída; inspirada na presença de Paulo Freire, marcava as diferentes dimensões da democratização possível naquele momento histórico e social. A herança autoritária presente na nossa história política deixou marcas também em nossas personalidades, por vezes pouco pacientes com posições e opiniões contrárias às nossas; por esse motivo destacamos aqui o processo de construção do consenso como um legado freiriano para a gestão.

\section{DREM E NAE - O TRABALHO DA CUNHA E O ENCONTRO COM A REALIDADE DA CIDADE}

A cunba é uma ferramenta utilizada em várias profissões e serve para mudar a direção de forças para auxiliar em algum trabalho... Aplica-se a força em uma direção, a cunha a transforma e a dirige para outra direção, normalmente perpendicular à força empregada. Ela também serve para calçar, nivelar, ajustar uma peça qualquer. O emprego dessa metáfora aqui vincula-se ao que classificamos como uma estratégia e uma tática política desenvolvida e aplicada tanto pelos agentes do governo, responsáveis por materializar o projeto político, quanto pelos trabalhadores, movimentos sociais, usuários das escolas e suas comunidades.

A gestão Freire e equipe da SME - como o governo em seu conjunto enfrentaram o desafio de compor, em curto espaço de tempo, quadros de pessoal para o conjunto dos órgãos centrais e regionais alinhados com a nova política. Os princípios da democratização da gestão da escola e maior participação de todos nas decisões, da democratização do acesso e da ampliação do atendimento a jovens e adultos, provocava tanto um grande entusiasmo e expectativas dos profissionais das escolas, como muita apreensão e um clima de confiança instável diante das mudanças, especialmente entre os diretores de escola.

As cinco DREM, criadas em 1978, foram ampliadas para dez pelo governo Jânio Quadros. O Decreto Municipal no 27.813, de 12/06/1989 que reorganizou parcialmente a SME registra, entre seus "Considerandos", a criação de Núcleos de Ação Educativa, tendo em vista os Núcleos Regionais de Planejamento; no Art. $3^{\circ}$ altera a denominação das DREM que passam a denominar-se NAE, subordinados à CONAE. (SÃO PAULO. SME, 1989).

Os NAE se transformam em um dos alicerces da proposta de descentralizaçãa desenvolvida pela Secretaria Municipal de Educação de uma nova proposta pedagógica, permitindo uma relação mais direta com a Sociedade Civil. (JACOBI, 1994, p. 133). Mas, em seus inícios, a apreensão sobre os quadros que as comandariam resultou na proposta inicial de fechamento das cinco novas DREM criadas no governo Jânio Quadros, retornando ao número de cinco. Assim, aos primeiros ocupantes dessa 
instância caberia a missão de fechamento da DREM-10, na região de São Miguel Paulista. Tal fato gerou grande resistência entre apoiadores da administração petista na região.

A narrativa desse acontecimento revela exatamente o processo de construção da gestão democrática e suas tensões e dissensos dentro e fora dos gabinetes. Tendo entre seus atores militantes sindicais, professores e gestores das redes municipal e estadual, coadjuvados pelos movimentos populares, argumentaram em favor da manutenção desse órgão descentralizado como um meio efetivo, uma condição para democratizar a própria educação.

O diálogo entre representantes locais da nova gestão e coletivos organizados produziu argumentos consistentes contra decisões apoiadas somente em dados quantitativos e destacou as diferenças substantivas no perfil da população das diversas regiões da ZL, apresentando a partir dessas singularidades, demandas específicas à educação que justificavam a organização e existência de pelo menos três NAE na região.

Um documento formal que relatou esses argumentos foi apresentado ao colegiado do NAE-10 e à SME, solicitando a permanência da DREM-10. $\mathrm{Na}$ prática esse movimento de interlocução com educadores e movimentos inaugurou o primeiro momento de participação direta do NAE-10 em favor da permanência de sua estrutura. O trabalho da cunba, forjada nessa disputa, resultou da participação e do esforço coletivo consolidado no Decreto $n^{\circ} 27.813 / 89$, que criou na ZL três Núcleos: NAE-7 (Penha), NAE-9 (Itaquera) e NAE-10 (São Miguel Paulista). Consideramos esse evento uma cunba manipulada a partir da sociedade civil.

Instalado, o NAE-10 passou a estabelecer diálogo com os profissionais das escolas da região, desafiado a recuperar prédios e providenciar condições materiais para reencontrar a bonitę̧a da escola, reconstruir relações entre gestores punidos na gestão anterior e órgãos regionais, formar equipes de trabalho, estabelecer diálogo e acolher movimentos regionais de educação, em especial o MEZL que assumiu protagonismo no processo de criação do MOVA-SP.

Nesse processo de aprendizado mútuo, sempre pacientemente impacientes ${ }^{8}$, educadores, escolas e comunidades, além do governo da educação municipal -geograficamente próximos e distantes - fizeram uso não apenas da cunba como estratégia e tática para intervir na execução das políticas propostas. Também o formão se fez presente na região.

8 Referência a Paulo Freire em publicação de $1^{\circ}$ de fevereiro de 1989 (D.O.M Suplemento): Aos que fazem a Educação Conosco em São Paulo. 


\section{A CUNHA E O FORMÃO: FERRAMENTAS DE URGÊNCIA NA GARANTIA DE DIREITOS}

Durante a gestão Freire foram enfrentados desafios urgentes e localizados que demandaram o enfrentamento da confusão, comum à época, que colocava ações voltadas à garantia de direitos como ações autoritárias, contrárias ao discurso da gestão democrática defendida pela SME. Democratizar a educação na cidade e a gestão da escola, para além da implementação de canais institucionais de participação, exigiu um aprendizado coletivo de cultura democrática; um processo valioso, porém lento, gradual, que ocorreu de modo plural na rede de ensino municipal.

Quase como um susto, os diretores se viram na posição central de operacionalizar grandes mudanças na escola e na relação com a comunidade. Se tomarmos a escola como um belvedere, um lugar a partir do qual se mira o entorno e, se nos colocarmos na perspectiva daqueles anos (e até dos atuais), quando educadores se viram tolhidos após um sopro de democracia, é preciso compreender as estratégias de autoproteção e até da transformação do belvedere em casamata, diante de administrações que se sucedem e desprezam os saberes e a inteligência da escola e de seus profissionais. Temos, portanto, que levar em consideração esse processo de resistência às mudanças nas ações derivadas da democratização da escola, mas principalmente àquelas voltadas à democratização do acesso.

Diante de resistências locais e até estratégias de sabotagem antecipada no âmbito do sistema, ${ }^{9}$ uma geometria política e militante se desenvolveu para a garantia do sentido público da educação municipal, do projeto anunciado, e das responsabilidades dos agentes públicos.

Todo processo administrativo público convive com urgências; em São Paulo e no NAE-10, registramos uma urgência inaugural, que comprometia o início do ano letivo em muitas escolas da rede em 1989: a falta de mobília para salas de aula novas, resultantes de reformas. Criadas, prontas, e sem carteiras. Com novas equipes estabelecidas ainda nas DREM a descoberta do problema foi considerada um desastre. $\mathrm{Na}$ busca de solução, descobriu-se que a mobília havia sido adquirida num convênio com o governo do Estado, porém, não havia sido retirada. A Administração Regional mobilizou caminhões, e o Núcleo, os braços para carregar e descarregar a carga, um final de semana antes do início das aulas.

9 Nos referimos aqui ao vivido na SME no início da gestão Paulo Freire e narrado por Arelaro (2019, p. 130), quanto à sabotagem nos computadores da secretaria - não a única - e a situação de ausência de informações centrais e vitais para a operação da Secretaria em janeiro de 1989. 
A cunha e o formão foram se forjando sob o calor das descobertas e aprendizados dos processos administrativos nas distintas escalas de gestão da educação de um município como São Paulo. Iniciava-se na prática uma relação dialógica em diferentes direções: endógena à SME, na medida em que as urgências aproximaram equipes para solucionar e aprender com problemas, e exógena, ao demandar e mobilizar colaboração central e regional entre secretarias.

O episódio ocorrido pouco antes do início do primeiro ano letivo da gestão Freire, demonstra a face de não neutralidade das ações e omissões de agentes públicos e a urgente necessidade de domínio de informações para o planejamento. O domínio do território educativo demandou o levantamento de dados para além das estatísticas, tarefa realizada em todas as dimensões pelas equipes de trabalho, ${ }^{10}$ em uma dinâmica de gestão colegiada do NAE e da partilha permanente, com intensa presença das equipes nas escolas e comunidades. A vivência da política educacional tornou cada agente do NAE um interlocutor qualificado a dialogar sobre problemas narrados pelas escolas, seus profissionais e comunidades. Os problemas e dificuldades detectados forneciam um mapa da situação e das demandas, que eram somadas àquelas apresentadas formalmente, ou reportadas pelos diretores diretamente.

Desse modo, antes mesmo da organização sistêmica da participação desejada, ouvir pessoas, olhar dentro e o entorno da escola, forneciam dados para organizar o planejamento ao atendimento das questões urgentes e mobilizar os meios para o funcionamento das escolas e o trabalho de seus profissionais.

As demandas foram sendo escalonadas pelo grau de urgência, parte exigindo atendimento imediato, e paulatinamente reunidas e tratadas em conjunto com escolas e comunidades, tendo no horizonte a elaboração do orçamento a partir dos princípios da descentralização, participação e autonomia das escolas, numa perspectiva sistêmica capaz. de criar as condições básicas para que a comunidade e a escola pudessem diagnosticar seus problemas e deliberar como resolvê-los (SÃO PAULO. SME, 1992, p. 4), portanto, um Planejamento de Baixo para Cima a partir desses três princípios básicos, o que significou investir nas pessoas e valorizar esforços de aproximação e diálogo de modo que a autonomia das escolas tivesse centralidade em seus Conselhos.

10 O NAE-10 operou com sete equipes de trabalho e setores: Equipe Pedagógica, Planejamento, EDA, Gestão Democrática, Supervisão, Administrativo e Financeiro. 


\section{O FORMÃO ENTALHANDO A \\ DEMOCRATIZAÇÃO DO ACESSO}

O trabalho de planejamento no NAE-10 envolveu informações vindas do coletivo e da fabricação singular de estatísticas locais que guiavam a ação no território, permitindo conhecer a demanda de matrículas na diversidade de atuação do sistema municipal de educação. De certo modo, o planejamento assumiu no âmbito da democratização do acesso, o trabalho do formão: o artefato utilizado para entalhar, esculpir. Permitiu dar visibilidade àquilo que era possível realizar depois de conhecer as lógicas de ocupação dos espaços físicos das escolas e de seu funcionamento; permitiu analisar os recursos educacionais públicos de ambas as redes (municipal e estadual) em sua contiguidade e olhar às demandas não atendidas no território, inclusive para compor o Plano Regional de Educação (SÃO PAULO. SME, 1992).

De modo inédito e aparentemente extirpado das práticas de planejamento local pelos governos que se sucederam, a experiência dos Grupos Locais de Diretores - GLD - foi viabilizada pelo diálogo iniciado em 1989 entre SME e Secretaria de Estado da Educação para o atendimento à $1^{\mathrm{a}}$ série do $1^{\circ}$ grau em 1990.

Esse experimento foi um marco de aprendizagem e atuação conjunta em benefício da população e propiciou uma experiência ímpar de gestão democrática e coletiva entre os diretores de escolas municipais e estaduais da região. Apesar da quase total ausência de registros e estudos sobre tal experiência, tomamo-la aqui para exemplificar o uso do formão na democratização do acesso e construção da autonomia das escolas como acontecimento inédito na região, que materializou a práxis local de gestão alinhada às diretrizes freirianas da SME, e para tanto narramos a dinâmica desse trabalho.

Os setores de Planejamento atuaram conjuntamente no mapeamento dos usos dos espaços escolares e respectivo atendimento na região. Esse trabalho resultou no aprendizado cooperativo de uma metodologia para o estudo do potencial ocioso dos equipamentos e formas de superar a falta de salas de aula necessárias ao pleno atendimento ${ }^{11}$. Foram identificadas salas repletas de materiais inservíveis, desativadas para manutenção, utilizadas como depósitos, destinadas a atividades que poderiam ser deslocadas para outros espaços, e outras situações por vezes incontornáveis. Visitar as entranhas físicas das escolas das duas redes

\footnotetext{
11 A singularidade dessa experiência esteve na partilha de conhecimento de uma tecnologia já presente no setor de Planejamento da $10^{\mathrm{a}} \mathrm{DE}$, em 1989, realizada por técnicos que tinham plena identidade com a diretriz da Democratização do Acesso na região.
} 
permitiu vislumbrar um inédito viável ${ }^{22}$ : dar atendimento àquela comunidade no máximo da capacidade, projetar ações necessárias à utilização dos espaços viáveis e um plano de construções conjunto, com a colaboração dos diretores de escola e suas equipes que conheciam de perto as comunidades.

O planejamento experimentado foi produzido de modo andarilho, ouvindo nas escolas as lógicas de ocupação dos espaços e tempos; conhecer os prédios escolares e sua ocupação tornou-se recurso de compreensão das políticas de gestão locais das escolas, traduzidas em práticas estabelecidas por vezes de modo personalista, tidas como imutáveis, acomodadas a um modus operandi que contrariava a função pública dos edifícios. Outras vezes, as visitas acompanhadas de funcionários da escola indicavam as providências necessárias para viabilizar a ampliação do atendimento.

Partilhadas as informações, desenvolvia-se um estudo preliminar para compor cenários em ambas as redes, tomando tanto a situação presente, quanto a projeção do funcionamento para o ano seguinte. Entre agosto e outubro, com o mapeamento realizado, os diretores eram solicitados a projetar o funcionamento futuro de suas escolas, enviar aos setores de planejamento e apresentar nos encontros dos GLD, em que eram colocados em comum Quadros Escolares (QE), e se podia visualizar a ocupação das escolas no ano em curso e a projeção do atendimento para o ano seguinte. Dessa operação de socialização de informações, iniciava-se a verificação do potencial de atendimento no território.

Apesar de os GLD terem sido pensados para dar atendimento conjunto entre Prefeitura e Estado à demanda da $1^{\text {a }}$ série, isso só podia ser obtido projetando o funcionamento total de cada escola para o ano seguinte, computando o número de egressos - que gerava novas demandas de atendimento em continuidade de estudos - a fim de obter espaços disponíveis à recepção de novos alunos de $1^{\circ}$ ano do $1^{\circ}$ grau.

Os agrupamentos de diretores eram feitos por proximidade geográfica e características da demanda em cada região. Essa práxis de planejamento, não restrita à racionalidade burocrática, acolhia a experiência e saberes dos diretores sobre as demandas locais com intensa transferência de informações entre as escolas. A socialização do modo de operação das unidades escolares produziu uma nova qualidade de relações profissionais; tanto empoderou os diretores,

12 Ao tratar do conceito de inédito-viável em Paulo Freire, Ana Freire (2020, p. 279, grifos da autora) assim o traduz: “(...) O "inédito-viável” é na realidade uma coisa inédita, ainda não claramente conhecida e vivida, mas sonhada e quando se torna um 'percebido destacado' pelos que pensam utopicamente, esses sabem, então, que o problema não é mais um sonho, que ele pode se tornar realidade. Assim, quando os seres conscientes querem, refletem e agem para derrubar as "situações-limites" que os e as deixaram a si e a quase todos e todas limitados a ser-menos o 'inédito-viável' não é ele mesmo, mas a concretização dele no que ele tinha antes de inviável. Vejase ainda: FREITAS (2020, p. 39-45), Prefácio ao livro de FREIRE, Pedagogia dos sonhos possíveis; PARO; VENTURA; e SILVA (2020), em ensaio sobre o constructo 'inédito viável', de Paulo Freire. 
na medida em que puderam tomar decisões cooperativas, assumindo demandas que, por vezes, alteravam o perfil de atendimento de seu público para viabilizar a outro diretor que ampliasse atendimento (por exemplo, de $2^{\circ}$ grau, não ofertado pela rede municipal na região), como deu visibilidade às condições de trabalho do conjunto das escolas quanto ao atendimento, revelando discrepâncias de esforços. Resistências individuais foram manifestas por pequena parcela dos diretores, porém, a mediação dos setores de planejamento e a atuação dos demais diretores dos grupos assumia a função do formão, na medida que o clima reflexivo e colaborativo do grupo de diretores induzia à mudança de posturas.

As decisões firmadas nesses encontros extrapolavam o atendimento à $1^{\text {a }}$ série; resultavam em compromissos mútuos de parte dos órgãos regionais para dar providências às necessidades desses acordos. Reparos físicos nos prédios, retirada de entulhos e materiais inservíveis, aquisição de mobílias, ampliação de espaços de uso comum e identificação de necessidades só solucionáveis com a construção de novas escolas, estavam na pauta de responsabilidades dos sistemas de ensino. Do trabalho conjunto entre 1989 e 1992 resultou um plano de obras desenhado localmente sob responsabilidade das duas redes de ensino. Parte do plano foi executado ainda naquela gestão; outra parte nos anos posteriores.

O formão estava materializado no trabalho de planejamento para conhecer as escolas e suas realidades, na capacidade de planejar reunindo e socializando informações, no exercício do potencial crítico de diretores e equipes das escolas, na associação local para a produção e o compromisso de levar a cabo um plano de intervenções e construções para aliviar o esforço imprescindível, porém limitado das escolas. $\mathrm{O}$ aprendizado adquirido no planejamento conjunto entre os diretores de ambas as redes foi assumido até 1992, numa performance que demonstrou ampliação do envolvimento e autonomia para o trabalho coletivo e capacidade de indicar soluções sistêmicas, de longa duração.

Os espaços formais à manutenção dessa aproximação e seu reconhecimento, no entanto, foi sendo substituído pela prática burocrática que prescindiu da inteligência local, prescindiu do sentido público e político da participação e diálogo. Localizamos documento do Sindicato de Especialistas de Educação do Magistério Oficial do Estado de São Paulo - UDEMO, de 2009, dirigido ao então Secretário de Estado da Educação Paulo Renato Souza, reivindicando o retorno de um espaço que havia para o trabalho das questões locais dessas escolas, que era conbecido pela sigla GLD - Grupo Local de Diretores: 
Esse era um espaço muito importante, onde os diretores mais novos tinham a oportunidade de receber orientações dos mais experientes, e onde as questões de todas as escolas da região eram discutidas, e até mesmo resolvidas, pelos diretores locais, com o apoio das Diretorias de Ensino. (...) Nossa experiência, no trabalho com os Grupos Locais de Diretores, foi muito positiva, razão pela qual reivindicamos de Vossa Excelência a reimplantação dessa política de trabalho. (UDEMO, 2009, p. 1)

Consideramos esse documento uma evidência do valor distintivo das relações de aproximação entre diretores de escolas públicas de uma mesma região, tal como vividas naquele período, para concretizar a anunciada autonomia da escola e a participação na gestão e na democratização do acesso.

\section{O RETORNO DA CUNHA PARA A DEMOCRATIZAÇÃO DO ACESSO AOS JOVENS TRABALHADORES E ADULTOS}

Se o planejamento do atendimento conjunto à demanda do ensino regular obrigatório operou como um formão no próprio processo de diálogo entre diretores e setores de planejamento das duas redes de ensino na região, a cunha precisou ser mobilizada para democratizar o acesso à educação de jovens trabalhadores ao ensino regular e de adultos na Suplência I (Alfabetização e Pós-alfabetização) e II (correspondente à segunda parte do ensino de $1^{\circ}$ grau) no turno noturno das escolas municipais. A ausência de funcionamento no turno noturno colaborava ao abandono dos que precisavam trabalhar e não permitia ampliar o atendimento a adultos sem escolaridade ou com escolaridade incompleta.

A cunha para a abertura do turno noturno foi a forma encontrada à garantia desse direito a jovens trabalhadores e adultos moradores dessas regiões. A título de ilustração registramos o processo de abertura do noturno em uma escola no bairro Cidade Kemel, em 1990. O uso de plenárias como estratégia para conduzir o tratamento de problemas com todos os envolvidos foi um meio importante à formação de consensos e tomada de decisões, como no exemplo aqui narrado.

Convocada pelo NAE-10, toda a comunidade escolar foi convidada. Com a presença da diretora da escola, professores, estudantes e moradores do bairro (que lotaram o pátio), o problema da falta de vagas noturnas para jovens trabalhadores e adultos foi colocado em discussão; debatida a questão apresentaram-se argumentos contrários e favoráveis. Os motivos contrários, apresentados pela equipe escolar, eram exatamente os vividos cotidianamente pela comunidade local que demandava essas vagas. Os populares explicaram aos docentes que eles moravam ali, que os problemas eram comuns a eles, e por essa razão se ajudavam mutuamente; que fariam o mesmo com a escola, colaborando e 
lutando para obterem mais recursos públicos para transporte, iluminação e outros. O NAE-10 também se comprometeu a encaminhar as demandas à Administração Regional e à SME. Da plenária resultou o consenso sobre a abertura do ensino noturno regular e a Suplência no ano seguinte. Nesse caso, a cunha - como estratégia - estava presente na relação entre escola, sua comunidade e o direito à educação.

Caso emblemático ocorreu em uma Escola Municipal de Primeiro Grau (EMPG) localizada no centro de São Miguel Paulista, privilegiada pela localização, provida de plenas condições de atendimento e funcionando apenas no turno diurno $^{13}$, indicada por esses atributos para abertura da Suplência e ensino regular à noite. Diante da indicação do NAE, o diretor aprovou, no Conselho de Escola, que a unidade não poderia abrir no turno noturno porque não bavia demanda e que não dispunba de professores e funcionários para garantir a segurança e o funcionamento normal das atividades escolares; argumentou ainda que como estávamos num momento de democracia, a decisão do Conselho da Escola deveria ser respeitada pelo NAE-10. De modo inequívoco a manifestação da escola (C.E.) denunciava e tensionava o princípio da Democratização do Acesso, assumido publicamente pela gestão Freire/Erundina. ${ }^{14}$

Diante da estratégia utilizada pelo diretor da escola, a cunba foi a demonstração cabal da existência da demanda: a escola foi orientada a iniciar o registro da demanda para o noturno; uma grande faixa colocada pelo NAE10, e divulgou-se a abertura de vagas para o noturno. Ao final de alguns dias o Supervisor foi informado pela escola de que não houve interessado; no entanto, havia no NAE-10 registros de reclamações sobre o não atendimento na escola. A ação seguinte foi repetir a orientação e trocar a faixa, agregando a seguinte mensagem: MATRÍCULAS NO NAE-10 Rua Ana Flora Pinheiro de Souza, 76, sala 10. Em menos de uma semana foram realizadas trezentas e sessenta pré-matrículas e determinado o funcionamento do turno noturno para o atendimento ao ensino regular noturno e a EDA.

A Educação de Adultos nas demais escolas não sofreu tais resistências; o diálogo e os consensos foram desenvolvidos em cada comunidade escolar; as escolas de educação infantil passaram a receber jovens e adultos em classes de alfabetização e as EMPG passaram a abrir no período noturno. Outras ações vinculadas à EDA ocorreram, não apenas nas escolas. A alfabetização e o Supletivo de $1^{\circ}$ Grau para os funcionários da Prefeitura foram realizados a partir

\footnotetext{
13 Utilizamos o termo "turno diurno" nesse artigo para designar os três turnos de funcionamento da escola entre $7 \mathrm{~h}$ e $19 \mathrm{~h}$ : manhã, intermediário e tarde.

14 Historicamente, atendendo uma demanda preferencial e privilegiada, a escola era também dirigida pelo antigo Delegado de Ensino da DREM-10.
}

690 - Rev. Bras. Polít. Adm. Educ. - v. 37, n. 2, p. 674 - 694, mai./ago. 2021 
do Programa Frente do Funcionalismo, ocupando inclusive espaços adaptados nos locais de trabalho à noite; do mesmo modo houve apoio ao MOVA e a entidades que atuavam com a EDA na região.

\section{IMPACIENTEMENTE PACIENTES - À BEIRA DE UMA CONCLUSÃO}

Nesse exercício de memória e análise das práticas de gestão colocadas em movimento há 32 anos, é possível afirmar a ousadia da gestão Freire, continuada por Mário Sergio Cortella e equipe da SME até 1992. A afirmação encontra evidências a cada passo quando elencamos quantidade, qualidade e potência das intervenções políticas no período.

Ao tratarmos da diretriz política da Democratização do Acesso na gestão Freire, sobre ela discorremos a partir das ações desenvolvidas pelo NAE-10, ancorados no âmbito do planejamento, que produziu ferramentas locais para envolvimento de diretores, escolas e seus Conselhos, não restritas à ampliação do atendimento. A elaboração de Projetos Pedagógicos próprios, em diálogo com um projeto maior de desenvolvimento educativo regional a ser expresso no orçamento da cidade (NAE-10, 1992), propunha fazer chegar às comunidades escolares a compreensão de que Projetos Pedagógicos sustentados na qualidade e na democratização da gestão custam dinheiro, e que, para serem mais que uma ficção, temos o direito e a capacidade para influir nas políticas, ao estilo do histórico MEZL. Esse foi um esforço de toda a administração da SME.

A experiência vivida sob a gestão e o ideário de Paulo Freire deixou como legado coragem para enfrentar adversidades. Propiciou a gerações de educadores, de meninos populares, a chance de conhecerem uma escola menos hostil, mais bonita, em que a inteligência e a criatividade puderam ser respeitadas, na qual o todo-poderosismo deixou de ser natural; aprendemos o gosto da liberdade, do risco de criar. (FREIRE, 1997, p. 10-11). Também aprendemos a ouvir, a participar da construção de consensos e a usar as ferramentas necessárias para defesa da escola pública quando pudemos diretamente fazê-lo. Em 1993, logo após o término da gestão Erundina, a região assistiu à fundação do Fórum de Educação da ZL, dando continuidade à defesa da escola pública popular (MENDONÇA, 2003).

Paulo Freire se fez cunha e formão naqueles anos para defender a escola pública municipal, os professores e professoras, os meninos populares, os jovens e adultos que puderam entrar nas escolas para aprender - mesmo quando sentados em mobília destinada aos pequenos... -; defendeu a boniteza necessária à escola 
para abrigar a todos. Fez uso dessas ferramentas dentro do governo, quando a lógica própria da administração, com seus constrangimentos e limites, colocava em risco a obra em processo.

As ferramentas do trabalhador manual ensinaram que a sobrevivência do consenso progressivo por vezes carece de forças internas e externas para calçar, nivelar, ajustar e até fender quando o kairós da prática política anuncia risco à possibilidade de ganho de um pouco mais de dignidade para todos.

\section{REFERÊNCIAS}

ARELARO, L.R.G. A Competência gestora de um grande educador. In FREIRE, P. Direitos humanos e educação libertadora: gestão democrática da educação pública em São Paulo. Rio de Janeiro/São Paulo: Paz e Terra, 2019. P. 307-324.

BRASIL. Constituição da República Federativa do Brasil de 1988.

Lei Ordinária n 9.394, de 20 de dezembro de 1996.

CASTELLS, M. Cidade, democracia e socialismo. Rio de Janeiro: Paz e Terra, 1980.

FARIA, V.E.P. A trajetória do Projeto CIEJA entre as políticas públicas de educação de jovens e adultos na cidade de São Paulo. 2014. Dissertação (Mestrado em Educação) - FEUSP, São Paulo.

FREIRE, A.M.A. Notas explicativas. In FREIRE, P. (Org.). Pedagogia da esperança: um reencontro com a pedagogia do oprimido. $27^{\mathrm{a}}$. ed. São Paulo: Paz e Terra, 2020.

FREIRE, P. Pedagogia do oprimido, 17ª . Ed. Rio de Janeiro, Paz e Terra, 1987 Professora sim, tia não. Cartas a quem ousa ensinar. São Paulo: Editora Olho d'Água, 1997.

Direitos humanos e educação libertadora: gestão democrática da educação pública em São Paulo. Rio de Janeiro/São Paulo: Paz e Terra, 2019. 
FREITAS, A.L.S. de. Pedagogia dos sonhos possíveis: a arte de tornar possível o impossível. FREIRE, P. Pedagogia dos sonhos possíveis. Ana Maria Araújo Freire (Org.). $3^{a}$ ed., Rio de Janeiro/São Paulo: Paz e Terra, 2020

GADOTTI, M.; JACOBI, P.R. Participação e descentralização: a experiência educacional do Município de São Paulo (1989-1992). Sistema Municipal de Educação: estratégias para sua implantação. Brasilia: MEC/SEF, 1994.

HADDAD, S.; DI PIERRO, M.C. Escolarização de jovens e adultos. Revista Brasileira de Educação. no 14, p. 108-194, mai/jun/jul/ago. 2000.

MARTINS, M. L. R. Descentralização e subprefeituras em São Paulo experiência da gestão 1989-1992: Prefeita Luiza Erundina de Sousa. FAU-USP, São Paulo, novembro 1997.

MENDONÇA, M. O Fórum de Educação da Zona Leste: participação e cidadania na luta por uma escola de qualidade. 2003. Dissertação (Mestrado em Educação) - FEUSP, São Paulo.

RIBEIRO, V.M. O Caminho da Escola. Luta popular pela escola pública. Cadernos do CEDI, n 15, 1986.

PARO, C.A.; VENTURA, M.; SILVA, E.K. Paulo Freire e o inédito viável: esperança, utopia e transformação na saúde. Trabalho, Educação e Saúde, v. 18, no 1, p. 1-22, 2020.

SÃO PAULO. (Município). Decreto ${ }^{\circ}$ 15.002, de 31 de março de 1978. Diário Oficial da Cidade. . Lei 27.813 de 12 de junho de 1989. Diário Oficial da Cidade. . SME. Construindo a educação pública popular. Caderno 22, out. 1990 . . SME. Planejamento: instrumento de mobilização popular. São Paulo: SME, 1992. 
SME. NAE-10. O orçamento Municipal e a Educação

em São Miguel Paulista. Plano Escolar. Plano Regional. Plano Orçamentário. Orçamento Programa 1993. São Paulo: NAE-10, 1992. (Cartilha) Mimeo.

UDEMO. Ofício no 116/09. São Paulo, 28 de setembro de 2009. Disponível em: www.udemo.org.br/Oficio 116_09.htm Acesso em 9 de março de 2021.

\section{Celia Benedicto Giglio}

Doutora em Educação pela Universidade de São Paulo, Programa de PósGraduação em Educação da Faculdade de Educação. Professora Associada da Universidade Federal de São Paulo, Escola de Filosofia, Letras e Ciências Humanas, Departamento de Educação, Guarulhos, SP, Brasil. Atuou como professora de Educação Básica nas redes públicas de ensino Municipal e Estadual de São Paulo - SP, de 1982 a 1997, e como diretora de escola Estadual de 1993 a 2006. E-mail: celia.giglio@unifesp.br

\section{Marcos Mendonça}

Mestre e Doutorando em Educação pela Universidade de São Paulo, Programa de Pós-Graduação em Educação da Faculdade de Educação. Diretor de escola aposentado da Prefeitura do Município de São Paulo - Secretaria Municipal de Educação, SP, Brasil. Atuou como professor de Educação Básica nas redes públicas de ensino Municipal e Estadual de São Paulo - SP, de 1979 a 1995, e como diretor de escola Municipal de São Paulo de 1995 a 2016. Atuou como Coordenador Regional de Educação entre 1989-1992 e 2000-2005; como Diretor Regional de Educação entre 2013-2016. Atuou como membro do Conselho Municipal de Educação de São Paulo de 2002 a 2013. E-mail: marcmendon@ gmail.com. 